November 2020

\title{
Using Prior Knowledge and Student Engagement to Understand Student Performance in an Undergraduate Learning-to-Learn Course
}

Sarah K. Davis

University of Victoria, skdavis@uvic.ca

Rebecca L. Edwards

University of Victoria, Rle@uvic.ca

Allyson F. Hadwin

University of Victoria

Todd M. Milford

University of Victoria

Follow this and additional works at: https://digitalcommons.georgiasouthern.edu/ij-sotl

\section{Recommended Citation}

Davis, Sarah K.; Edwards, Rebecca L.; Hadwin, Allyson F.; and Milford, Todd M. (2020) "Using Prior Knowledge and Student Engagement to Understand Student Performance in an Undergraduate Learningto-Learn Course," International Journal for the Scholarship of Teaching and Learning: Vol. 14: No. 2, Article 8.

Available at: https://doi.org/10.20429/ijsotl.2020.140208 


\title{
Using Prior Knowledge and Student Engagement to Understand Student Performance in an Undergraduate Learning-to-Learn Course
}

\begin{abstract}
This study examined prior knowledge and student engagement in student performance. Log data were used to explore the distribution of final grades (i.e., weak, good, excellent final grades) occurring in an elective under-graduate course. Previous research has established behavioral and agentic engagement factors contribute to academic achievement (Reeve, 2013). Hierarchical logistic regression using both prior knowledge and log data from the course revealed: (a) the weak-grades group demonstrated less behavioral engagement than the good-grades group, (b) the good-grades group demonstrated less agentic engagement than the excellent-grades group, and (c) models composed of both prior knowledge and engagement measures were more accurate than models composed of only engagement measures. Findings demonstrate students performing at different grade-levels may experience different challenges in their course engagement. This study informs our own instructional strategies and interventions to increase student success in the course and provides recommendations for other instructors to support student success.
\end{abstract}

\section{Keywords}

academic achievement, higher education, student engagement, student success

\section{Creative Commons License}

c) (i) $९$

This work is licensed under a Creative Commons Attribution-Noncommercial-No Derivative Works 4.0 License.

\section{Cover Page Footnote}

Support for this research was provided by an Insight Grant for research to Hadwin, A.F., \& Winne P.H. from the Social Sciences and Humanities Research Council of Canada (435-2012-0529). 
IJ-SoTL, Vol. 14 [2020], N0. 2, Art. 8

\title{
Using Prior Knowledge and Student Engagement to Understand Student Performance in an Undergraduate Learning-to-Learn Course
}

\author{
Sarah K. Davis, Rebecca L. Edwards, Allyson F. Hadwin, and Todd M. Milford \\ University of Victoria
}

Received: 8 September 2019; Accepted: 4 May 2020

\begin{abstract}
This study examined prior knowledge and student engagement in student performance. Log data were used to explore the distribution of final grades (i.e., weak, good, excellent final grades) occurring in an elective undergraduate course. Previous research has established behavioral and agentic engagement factors contribute to academic achievement (Reeve, 2013). Hierarchical logistic regression using both prior knowledge and log data from the course revealed: (a) the weak-grades group demonstrated less behavioral engagement than the goodgrades group, (b) the good-grades group demonstrated less agentic engagement than the excellent-grades group, and (c) models composed of both prior knowledge and engagement measures were more accurate than models composed of only engagement measures. Findings demonstrate students performing at different grade-levels may experience different challenges in their course engagement. This study informs our own instructional strategies and interventions to increase student success in the course and provides recommendations for other instructors to support student success.
\end{abstract}

Understanding factors contributing to student academic success is important for instructors, students, and institutions. Engagement is a malleable, multidimensional student-initiated pathway to important educational outcomes, including academic achievement (Fredericks et al., 2004; Reeve, 2013). Student engagement research often relies on self-report measures (e.g., Schmidt et al., 2017). However, there is growing interest in student engagement in online course environments using log data. The actions students take within an online course environment represent a form of student engagement: log data pulled from an educational technology is a partial record of engagement. Thus, student engagement is a particularly fruitful topic of inquiry for instructors looking to use learning analytics (Pardo, 20I4) with the potential to inform positive, proactive, and timely intervention in the learning process.

As use of educational technologies becomes more prevalent in education, learning analytics using log data is an increasingly common method to investigate student academic success and performance across faculties and disciplines (e.g., Fritz, 201 I; Kim et al., 20I6; Tempelaar et al., 20I5). Learning analytics are "the measurement, collection, analysis, and reporting of data collected during the learning process to inform and support students in achieving academic success" (Siemens \& Gašević, 2012, p.l). Instructors' use of learning analytics within a course could be an in-the-moment way to make sense of factors which contribute to success in that course and could lead to instructors taking action to support their students (Siemens, 20I3).

Learning analytics has recently emerged as a discrete academic discipline due to the rise of big data and the relatively new capacity for stakeholders to access and analyze complex learning data sets (Long \& Siemens, 20I I; Siemens \& Baker, 20I2). Due to the widespread use of learning management systems (LMS) and other educational technologies, instructors can (a) access records of their students' actions within a course, (b) focus in on important actions associated with learning, (c) evaluate if their students are engaging in those actions, and (d) intervene appropriately. Similarly, students may also access information about their performance and engagement, depending on the reports and/or visualizations provided within the LMS. Log data created during the learning process can be leveraged to empower learners and instructors (Siemens \& Baker, 2012). Learning analytics have potential to (a) assess in-the-moment factors contributing to success in a course, and (b) inform instructional decisions and action in support of students (Siemens, 2013).

Previous learning analytic studies have focused on log file data captured within the LMS to predict student achievement (e.g., Macfadyen \& Dawson, 20I0), and many institutions have adopted systems that draw on log data to predict students who are at risk of failure. However, the utility of data captured by the LMS may be limited due to its complexity (Pardo, 20I4). There could be any number of reasons to explain student data captured by the LMS. Recorded traces of student actions in an online course environment require awareness of the context; therefore, the instructor plays an important role in the contextual interpretation of any log data. These data also represent students' engagement in the course, even though the data may be incomplete. Further, student engagement represents a place where instructors could intervene positively and proactively based on how students are interacting with the course LMS.

However, student activity within a course LMS is influenced by the many factors students bring with them into the course. Often, research using log data ignores the importance of prior knowledge. Educational psychologists have long recognized the importance of prior knowledge when researching student learning (e.g., Cogliano et al., 20 I8; Dunlosky et al., 20I3; Shapiro, 2004). Prior knowledge is strongly correlated with student achievement (e.g., Simonsmeier et al., 2018), and should be considered in any research exploring differences in student performance.

Previous research on prior knowledge has examined broad conceptualizations of the role of prior knowledge in learning relevant to all domains. For example, compared to students with lower prior knowledge, students with higher prior knowledge: (a) have a higher level of comprehension of multimedia resources (Richter et al., 20 I6); (b) report lower cognitive load (Kalyuga et al., 1998); and, (c) may need different types of feedback (Fyfe \& Rittle-Johnson, 2016). Not knowing the levels of knowledge students possess before a research study on academic perfor- 
mance can make findings difficult to interpret or to control for prior knowledge. However, one barrier to incorporating prior knowledge into learning analytics research is access to measures of prior knowledge. Instructors might not have access to institutionally collected data while they are teaching, for example students' prior semester's GPA, which is often used as a proxy for prior knowledge.

The course context for this study was an elective educational psychology course with a blended design. Student performance in the course was evaluated based on the wording in the university's grading scale which distinguishes between levels of course material comprehension and engagement, see Figure I. According to the grading scale, students who receive a $\mathrm{C}+$ and lower (weak performance) display an adequate comprehension of course material and minimal to basic participation in activities. Students who receive a $\mathrm{B}-, \mathrm{B}$, or $\mathrm{B}+$ (good performance) demonstrate good comprehension, command of skills, and a more complex understanding of the course material. Finally, students who receive an $A-, A$, or $A+$ (excellent performance) show mastery of the course material and go beyond the expectations of the course. Thus, examining differences between three performance levels (i.e. weak, good, excellent) using log data and course activities post-hoc has potential to (a) indicate what elements of the course are related to student membership in each group, and (b) how instructors and students can use this information while the course is in progress.

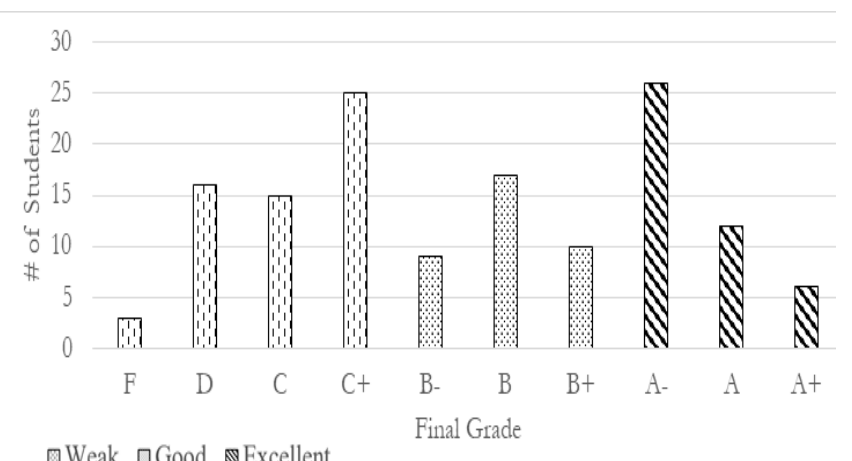

@Weak $\square$ Good $\mathbb{\$}$ Excellent

Figure I. Final grade for course divided into three student performance groups: weak, good, excellent.

\section{THEORETICAL FRAMEWORK Student Engagement}

Current research in educational psychology on student engagement focuses on measuring and examining the facilitators, indicators, and outcomes involved in both engagement and disengagement within a complex framework (Sharkey et al., 20I4). The exploration of student engagement started with disengagement and the need to identify variables in academic environments contributing to student engagement (Finn, 1993). Several frameworks of student engagement exist (e.g., Appleton et al., 2008; Fredericks et al., 2004). Appleton et al.'s (2008) model consists of academic, behavioral, cognitive, and psychological engagement. Operationalizing academic engagement as its own category would downplay the complex processes students engage in during academic tasks, indicating behavioral, cognitive, and psychological processes are not used during academic engagement.
Therefore, this study uses Fredricks et al. (2004) model that defines three dimensions of student engagement: behavioral, emotional, and cognitive. Reeve (20l3) additionally suggests agentic engagement should be added to form a four-factor model of student engagement. These four factors provide a holistic approach and attempt to capture the myriad processes involved in learning in university. This model also indicates any or all of these factors could be engaged during learning and academic activities.

Behavioral engagement. Students who are behaviorally engaged attend and participate in classes without disruptive or negative behaviors (Fredericks et al., 2004). School rules and norms are adhered to and followed. Course participation is included in behavioral engagement because definitions of the word "engagement" include involvement and commitment. The effort, attention, and persistence students show in learning activities are considered behavioral engagement (Reeve, 2013).

Emotional engagement. Emotional engagement includes students' experiences and beliefs about belonging, interest, and/or enjoyment in education (Trowler, 2010). Definitions of emotional engagement vary in the literature and focus on either positive or negative emotions experienced in education (e.g., Fredricks et al., 2004), or motivational constructs such as interest, attainment value, utility value/importance, and cost (Eccles et al., 1983). Students' emotions in educational environments include interest, boredom, happiness, sadness, and/or anxiety (Fredericks et al., 2004). These reactions may foster or erode a sense of belonging to the academic institution and society and influence students' willingness to complete work.

Cognitive engagement. Cognitively engaged students seek challenges, set goals, and are strategic self-regulators (Trowler, 2010 ; Fredericks et al., 2004). Students may experience a range of cognitive engagement in that they may be strategic and invested in learning or they may only be strategic when necessary to get good grades (Fredericks et al., 2004). Or, students may be motivated to learn but lack the requisite skills or strategies for success. The strategic use of sophisticated learning strategies, such as elaboration instead of memorization, comprises cognitive engagement (Reeve, 2013).

Agentic engagement. Reeve (20I3) augmented the three dimensions of engagement proposed by Fredricks et al. (2004), with a fourth dimension arguing agentic engagement should be included to capture proactive strategies students use to engage in their learning. Bandura (2008b), defines human agency as the use of intentionality, forethought, self-reactiveness, and self-reflectiveness to stimulate and control ones' own actions. Students' agency creates a learning environment that is motivationally more self-supportive.

As evidenced by the definitions of these four factors, student engagement is heavily dependent on the context in which it occurs (Kahu, 20 I I; Schmidt et al., 2017). Previous research has examined students' engagement within online courses, but has yet to examine students' activity data within a course's LMS as representative of student engagement (Soffer \& Cohen, 2018). Categorizing log data according to the factors of student engagement defined here has the potential to reveal differences in student performance in a course. 


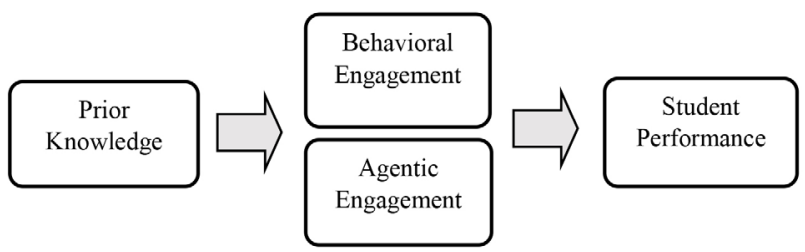

Figure 2. Graphical representation of the concepts used in this study.

\section{PURPOSE AND RESEARCH QUESTIONS}

Due to the paucity of research using student engagement to categorize log data, we focused on behavioral and agentic engagement for this exploratory study. Previous research based upon self-report data found the four factors of engagement account for $25 \%$ of the variance in predicting academic achievement (Reeve, 20I3). However, only two of the four factors were individually significant: behavioral and agentic. This is not to discount the salience of all four factors of student engagement. Rather, we aimed to (a) replicate Reeve's (20I3) findings with non-self-report data, and (b) focused on log data easily accessible and labelled as either behavioral or agentic engagement. Finally, in our course context, our log data cannot be categorized as emotional or cognitive engagement. Our focus on behavioral and agentic engagement in this study also recognizes other instructors may not have easily accessible indicators of these two factors available to them.

Therefore, the purpose of this study was to use prior knowledge information and log data to better understand differences in student performance in our course, to inform our future teaching practices, and to guide other instructors who seek to use log data from their own blended courses with practical implications from this study. This study examined prior knowledge, and behavioral and agentic engagement as predictors of student performance in a learning-to-learn course. The graphical representation of this model is shown in Figure 2 and is organized temporally with prior knowledge leading into behavioral and agentic engagement and ending with student performance.
Two research questions were examined:

I. How do measures of prior knowledge, behavioral engagement, and agentic engagement predict students' final performance group (i.e. weak, good, and excellent) in the course?

\section{When comparing models composed of pri- or knowledge and/or engagement variables, which model(s) most accurately predicts group membership (i.e. weak, good, excel- lent) in the course?}

\section{RESEARCH DESIGN AND METHODS Educational Context and Participants}

This elective educational psychology course at Institution I was designed to help students apply self-regulated learning (SRL) theory framed by Winne \& Hadwin (1998) and practice to their concurrent academic courses. The course exposed students to a variety of regulatory skills, strategies, and beliefs meant to improve their approaches to learning. Other topics covered in the course included procrastination, motivation and emotion, time management, test anxiety, and collaboration. The I3- week elective course consisted of a weekly 90 -minute lectures and 90 -minute labs in which students applied lecture material in a blended online environment. Success in this course required students use the LMS in specific ways, both during class time and outside of class time. Due to the lecture and lab requirement for this course, students needed to view the LMS a minimum of three separate times each week to complete the required assignments for the course.

Consenting participants were 139 students from a mid-sized, non-urban Canadian university in the January term of 2016. Students were primarily first year $(52 \%)$ and enrolled in at least one other academic course concurrently. Participants' mean age was I9.2I (SD = I.56; 45\% female). Students were from a range of

\begin{tabular}{|c|c|c|c|}
\hline Category & $\begin{array}{l}\text { Variable name } \\
\text { (Abbrev.) }\end{array}$ & Variable description & Example item(s) \\
\hline \multirow{2}{*}{$\begin{array}{l}\text { Prior } \\
\text { knowledge }\end{array}$} & $\begin{array}{l}\text { Concept } \\
\text { pre-assessment } \\
\text { (prior-CP) }\end{array}$ & $\begin{array}{l}\text { The concept pre-assessment administered during week I of the course } \\
\text { consisted of } 20 \text { multiple choice questions about course concepts: range } 20- \\
90 \text {. Cronbach's alpha of } .603 \text {. }\end{array}$ & $\begin{array}{l}\text { What do good goals help you do? } \\
\text { Which of the following does not influ- } \\
\text { ence motivation? }\end{array}$ \\
\hline & $\begin{array}{l}\text { Previous } \\
\text { semester's grade } \\
\text { point average } \\
\text { (GPA; prior-GPA) }\end{array}$ & $\begin{array}{l}\text { Average GPA received during the Fall } 2015 \text { semester. Computed on a } \\
10 \text {-point scale by the university: range } 0-9 .\end{array}$ & ( \\
\hline \multirow{3}{*}{$\begin{array}{l}\text { Behavioral } \\
\text { Engagement }\end{array}$} & $\begin{array}{l}\text { MyPlanner } \\
\text { (beh-MP) }\end{array}$ & $\begin{array}{l}\text { An online questionnaire filled out weekly. Students set a goal for an upcom- } \\
\text { ing study session and, following the session, students reflected on their goal } \\
\text { and the challenges they faced. The number of MyPlanners students fully } \\
\text { completed comprised this variable: range I-IO. }\end{array}$ & $\begin{array}{l}\text { My learning goal for this two-hour study } \\
\text { session is... } \\
\text { How much of a challenge or success } \\
\text { were each of these during the last week? }\end{array}$ \\
\hline & $\begin{array}{l}\text { Lecture synthesis } \\
\text { activities (beh-LS) }\end{array}$ & $\begin{array}{l}\text { Activities available for students to complete at the end of the weekly lecture. } \\
\text { Consisted of three questions. The instructor marked five randomly selected } \\
\text { activities. The number of lecture synthesis activities students completed } \\
\text { comprised this variable: range I-9. }\end{array}$ & $\begin{array}{l}\text { Think about the activity we did in class } \\
\text { and the attributes of a CAST goal. Which } \\
\text { one of the following is a better goal? }\end{array}$ \\
\hline & $\begin{array}{l}\text { Regulation of } \\
\text { Learning } \\
\text { Questionnaire } \\
\text { (beh-RLQ) }\end{array}$ & $\begin{array}{l}\text { The RLQ (Author, 20I5) assessed a student's perceptions of their SRL } \\
\text { processes. Students completed the RLQ two times (weeks two and eleven). } \\
\text { Reflection on the experience was a major lab component. However, comple- } \\
\text { tion was not graded.This variable was coded as number of RLQs complete: } \\
\text { range } 0-2 \text {. }\end{array}$ & $\begin{array}{l}\text { Think of a recent challenge you have } \\
\text { faced in your academic learning. When } \\
\text { you answer the questions throughout } \\
\text { this questionnaire, think about that } \\
\text { specific challenge. }\end{array}$ \\
\hline $\begin{array}{l}\text { Agentic } \\
\text { Engagement }\end{array}$ & $\begin{array}{l}\text { Days viewed } \\
\text { course } \\
\text { (agen-Days) }\end{array}$ & $\begin{array}{l}\text { Logs from the LMS revealed the number of unique days a student accessed } \\
\text { the course: range } 23-84 \text {. }\end{array}$ & N/A \\
\hline $\begin{array}{l}\text { Outcome } \\
\text { Variable }\end{array}$ & $\begin{array}{l}\text { Group member- } \\
\text { ship }\end{array}$ & $\begin{array}{l}\text { The final grade distribution for the course showed three groups: weak-F } \\
\text { through } C+(n=59) \text {, good-B- to } B+(n=36) \text {, excellent-A- to } A+(n=44) \text {. }\end{array}$ & N/A \\
\hline
\end{tabular}




\begin{tabular}{|c|c|c|c|c|c|c|}
\hline Variable Name & $\begin{array}{c}\text { Total Missing } \\
\text { in Variable }\end{array}$ & $\begin{array}{l}\text { Missing Weak } \\
\text { Group }\end{array}$ & $\begin{array}{l}\text { Missing Good } \\
\text { Group }\end{array}$ & $\begin{array}{c}\text { Missing Excellent } \\
\text { Group }\end{array}$ & $\begin{array}{l}\text { Pearson Chi- } \\
\text { Square }\end{array}$ & $\begin{array}{c}\text { Directional Symmetric } \\
\text { Measure }\end{array}$ \\
\hline Concept pre-assessment & 14 & 12 & I & I & $\begin{aligned} X 2 & =11.936 \\
p & =.003\end{aligned}$ & $\eta 2=.086$ \\
\hline
\end{tabular}

faculties on campus, including social sciences, business, humanities, science, and engineering.

\section{DATA SOURCES AND PROCEDURES}

The ethics committee at the university approved all procedures. All measures were (a) completed online as a part of the lecture, lab, or homework, (b) collected from institutional data, or (c) log data collected from the LMS. None of the measures contributed to the overall mark students received in the course. The outcome variable, performance group membership, was derived from the final course grade. In total, data were collected from eight sources grouped into three categories: (a) prior knowledge, (b) behavioral engagement, and (c) agentic engagement (see Table I).

Performance group membership. Students were divided into three groups based on their final grades in the course (a) the weak-grades group who achieved grades of $F$ to $C+(n=59)$, (b) the good-grades group who achieved grades of $B-$ to $B+(n=36)$, and $(c)$ the excellent-grades group who achieved grades of $A-$ to $A+(n=44$; see Figure I).

Prior knowledge. In our study, we used two measures to represent prior knowledge (a) previous semester's GPA from institutional data (prior-GPA), and (b) a concept pre-assessment (prior-CP) given at the beginning of the course during class time.

Behavioral and agentic engagement. Data on behavioral and agentic engagement was categorized according to potential indicators to replicate Reeve's (2013) findings. Indicators of behavioral engagement include the number of completed MyPlanners (beh-MP), lecture synthesis activities (beh-LS), and Regulation of Learning Questionnaires (beh-RLQ). All three activities were required components of the course and as such completion was a measure of behavioral engagement. The indicator of agentic engagement was the days viewed course (agen-Days), see Table I. This represents the assumption that students who were on the course LMS more days than the expected minimum of three days per week would be engaging in a range of proactive learning activities, for example reviewing the lecture slides, interpreting feedback on assignments, and preparing for future lectures and assignments. The minimum of three days per week was not explicitly mentioned in the course syllabus but was implied by the structure of the weekly required activities in the course.

Missing data. For most of our variables, we used log file data collected during the learning process, so there was no missing data for those variables. However, we were missing data from one of our measures, the concept pre-assessment, for a total of I4 students (see table 2). Chi-square analyses determined values were more likely to be missing from the weak group (see table 2). Multiple imputations were not possible as assumptions for data missing completely at random (MCAR) was not met; thus, we addressed missing data through pairwise deletion.

\section{ANALYSIS AND FINDINGS}

\author{
RQI: How do measures of prior knowledge, \\ behavioral engagement, and agentic engage- \\ ment predict students' final performance \\ group (i.e. weak, good, and excellent) in the \\ course?
}

Three binary hierarchical logistic regression analyses (weak/good, weak/excellent, good/excellent) were performed (see table 3). We employed hierarchical logistic regression over multinomial stepwise logistic regression so we could enter the variables according to theory rather than rely on variables entered stepwise based on statistical merit alone. From the variables outlined in Table I, those correlating with group membership at $>0.2$ and $<0.8$ were included in the logistic regression analyses performed to predict (a) group membership for participants and (b) differences between groups.

The variables were entered in blocks to control for the prior knowledge variables (i.e. prior-GPA and prior-CP), based on the importance of prior knowledge in educational psychology research. Therefore, the predictor variables were entered in two blocks (a) block one: prior knowledge (prior-CP and priorGPA), and (b) block two: engagement variables (beh-RLQ, beh-MP, beh-LS, and agen-Days). All three models were statistically significant at both blocks one and two, see Table 4. For all three models, block two led to the best prediction accuracy of group membership: (a) weak/excellent $92.1 \%$, (b) good/excellent $74.4 \%$, and (c) weak/good $80.2 \%$.

An increase in Prior-GPA significantly increased the odds of belonging to (a) the excellent performance group in both the weak-excellent model and good-excellent models, and (b) the good performance group in the weak-good model. A decrease in beh-LS significantly increased the odds of belonging to the weak performance group in both the weak-excellent model and weakgood models. An increase in agen-Days significantly increased the odds of belonging to the excellent performance group in the good-excellent model. Prior-CP, beh-MP, and beh-RLQ did not significantly increase the odds of belonging to a particular performance groups in any of the models.

\section{RQ 2: When comparing models composed of prior knowledge and/or engagement vari- ables, which model(s) most accurately pre- dicts group membership (i.e. weak, good, ex- cellent) in the course?}

The findings from RQI showed differences comparing the factors in predicting performance group membership for our students. For RQ2, we examined models comprised of different combinations of variables (prior knowledge and log data) to see which combination most accurately predicted group membership. We compared three new models containing variables that were significant in RQI, see Models 2- 4 in Table 5.

Findings from the analyses revealed, other than the original Model I, the most effective model to predict group membership between weak and excellent group students is Model 3 includ- 


\begin{tabular}{|c|c|c|c|c|c|c|}
\hline Performance Group & Prior-GPA & Prior-CP & Beh-MP & Beh-LS & Beh-RLQ & Agen-Days \\
\hline & Mean(SD) & Mean(SD) & Mean(SD) & Mean(SD) & Mean(SD) & Mean(SD) \\
\hline Weak $(n=59)$ & $2.94(I .4 I)$ & $58.94(14.78)$ & $8.15(1.79)$ & $6.44(1.29)$ & $1.49(.68)$ & $38.5 I(8.54)$ \\
\hline Good $(n=36)$ & $4.38(1.60)$ & $64.29(12.07)$ & $9.36(.76)$ & $8.11(.98)$ & $1.86(.42)$ & $44.22(8.34)$ \\
\hline Excellent $(n=44)$ & $6.44(1.45)$ & $66.74(12.77)$ & $9.77(.52)$ & $8.39(.72)$ & $1.93(.25)$ & $52.16(9.70)$ \\
\hline Overall $(N=139)$ & $4.42(2.09)$ & $63.12(13.70)$ & $8.98(1.45)$ & $7.49(1.39)$ & $1.73(.55)$ & $44.31(10.57)$ \\
\hline
\end{tabular}

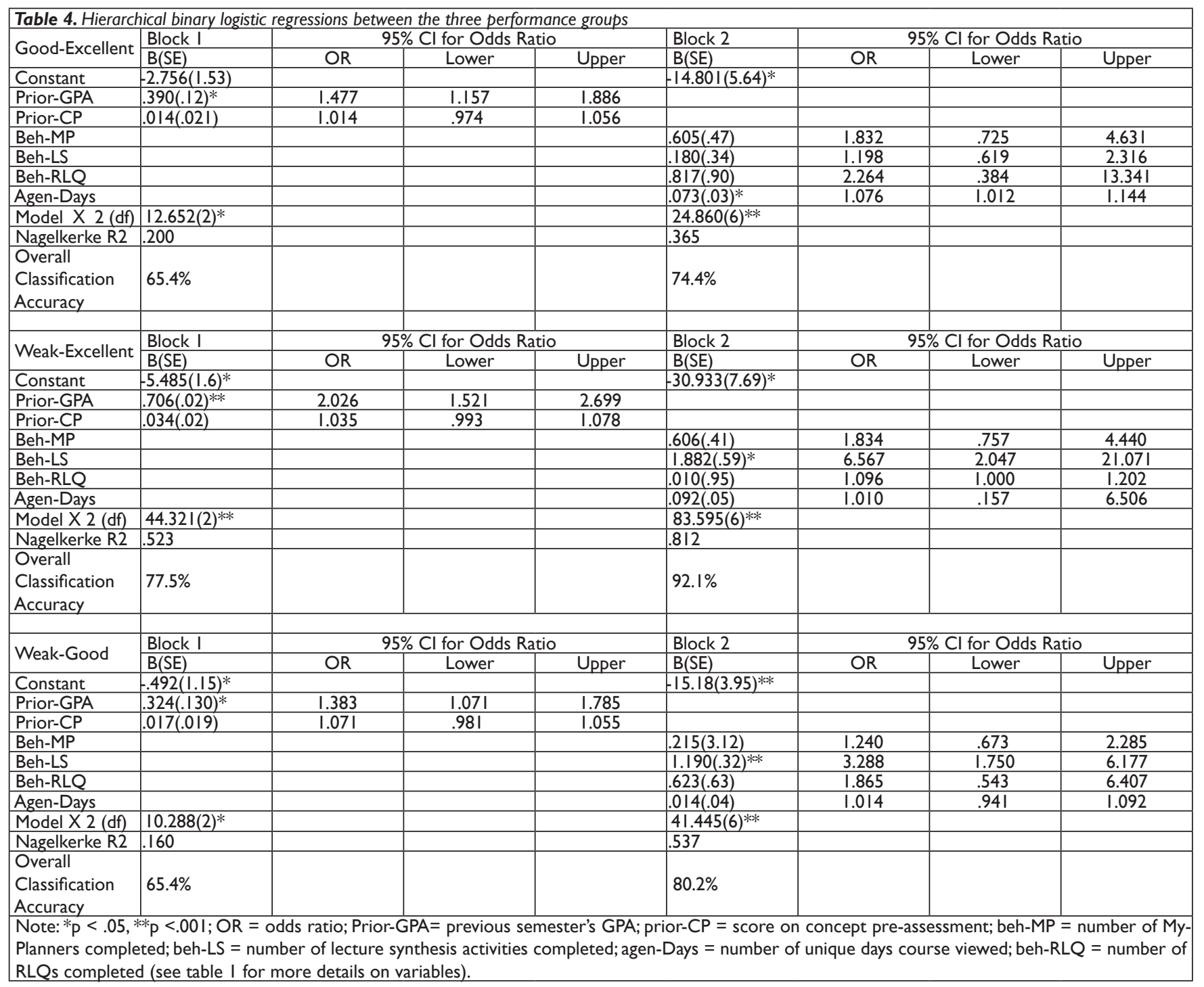

\begin{tabular}{|c|c|c|c|c|}
\hline Weak-Excellent & $\begin{array}{l}\text { Model I: } \\
\text { Prior knowledge and all log data }\end{array}$ & $\begin{array}{l}\text { Model 2: } \\
\text { Significant log data only }\end{array}$ & $\begin{array}{l}\text { Model 3: } \\
\text { GPA and log data }\end{array}$ & $\begin{array}{l}\text { Model 4: } \\
\text { CP and log data }\end{array}$ \\
\hline Block I Variables & Prior-GPA, Prior-CP & \begin{tabular}{|l|} 
Beh-LS, \\
Agen-Days
\end{tabular} & Prior-GPA & Prior-CP \\
\hline Nagelkerke R2 & .523 & .704 & .524 & .100 \\
\hline$\times 2(d f)$ & $44.32(2)^{* * *}$ & $76.484(2)^{* *}$ & $50.528(\mathrm{I})^{* * *}$ & $7.012(1)^{*}$ \\
\hline Sig. predictor(s) & Prior-GPA** & Beh-LS**, Agen-Days* & Prior-GPA ** & Prior-CP* \\
\hline Overall classification accuracy & $77.5 \%$ & $84.5 \%$ & $79.4 \%$ & $62.2 \%$ \\
\hline Block 2 Variables & \begin{tabular}{|l|} 
Beh-MP, \\
Beh-LS, \\
Beh-RLQ, \\
Agen-Days \\
\end{tabular} & & $\begin{array}{l}\text { Beh-LS, } \\
\text { Agen-Days }\end{array}$ & $\begin{array}{l}\text { Beh-LS, } \\
\text { Agen-Days }\end{array}$ \\
\hline Nagelkerke R2 & .812 & & .778 & .781 \\
\hline$\times 2(d f)$ & $83.595(6)^{* *}$ & & $88.5 \mid 3(3)^{* *}$ & 79.859(3)** \\
\hline Sig. predictor(s) & $\begin{array}{l}\text { Beh-LS* } \\
\text { Agen-Days }\end{array}$ & & Beh-LS*,Agen-Days* & Beh-LS*,Agen-Days* \\
\hline Overall classification accuracy & $92.1 \%$ & & $91.2 \%$ & $90 \%$ \\
\hline
\end{tabular}




\begin{tabular}{|c|c|c|c|c|}
\hline Good-Excellent & $\begin{array}{l}\text { Model I: } \\
\text { Prior knowledge and log data }\end{array}$ & $\begin{array}{l}\text { Model 2: } \\
\text { Significant log data only }\end{array}$ & $\begin{array}{l}\text { Model 3: } \\
\text { GPA and log data }\end{array}$ & $\begin{array}{l}\text { Model 4: } \\
\text { CP and log data }\end{array}$ \\
\hline Block I Variables & Prior-GPA, Prior-CP & $\begin{array}{l}\text { Beh-LS, } \\
\text { Agen-Days }\end{array}$ & Prior-GPA & Prior-CP \\
\hline Nagelkerke R2 & .200 & .212 & .211 & .013 \\
\hline$X 2(d f)$ & I2.652(2)* & I3.803(2)* & 13.722(I)** & $.764(\mathrm{I})$ \\
\hline Sig. predictor(s) & Prior-GPA* & Agen-Days* & Prior-GPA* & $\mathrm{N} / \mathrm{A}$ \\
\hline Overall classification accuracy & $65.4 \%$ & $63.8 \%$ & $65 \%$ & $50 \%$ \\
\hline Block 2 Variables & \begin{tabular}{|l|} 
Beh-MP, \\
Beh-LS, \\
Beh-RLQ, Agen-Days
\end{tabular} & & \begin{tabular}{|l} 
Beh-LS, \\
Agen-Days
\end{tabular} & $\begin{array}{l}\text { Beh-LS, } \\
\text { Agen- } \\
\text { Days }\end{array}$ \\
\hline Nagelkerke R2 & .365 & & .333 & .242 \\
\hline$X 2(d f)$ & $24.860(6)^{* * *}$ & & $22.886(3)^{* * *}$ & $15.548(3)^{*}$ \\
\hline Sig. predictor(s) & Agen-Days* & & Agen-Days* & Agen-Days* \\
\hline Overall classification accuracy & $74.4 \%$ & & $72.5 \%$ & $64.1 \%$ \\
\hline
\end{tabular}

ing prior-GPA, beh-LS, and agen-Days (Nagelkerke $\mathrm{R}^{2}=.778$; see table 5). Model 3 was able to classify $91 \%$ of students accurately. This was higher than Model 2 with just the log data (Nagelkerke $\mathrm{R}^{2}=.704$; model accuracy $=84.5 \%$ ) or Model 4 (Nagelkerke $\mathrm{R}^{2}=$ .781 ; model accuracy $=90 \%)$. Individual significant variables across all models were beh-LS, agen-Days, and prior-GPA.The prior-CP was also significant when it was the only measure of prior knowledge in Model 4.

Other than the original Model I, the most effective model to predict group membership between good and excellent group students is Model 3 including prior-GPA, beh-LS, and agen-Days (Nagelkerke R2 = .333; see table 6 ) with $72.5 \%$ of students correctly classified. This was higher than Model 2 with just the log data (Nagelkerke R2 = .212; model accuracy $=63.8 \%$ ) or Model 4 (Nagelkerke R2 = .242; model accuracy $=64.1 \%$ ). Individual significant variables across all models were agen-Days and prior-GPA. The prior-CP was not significant when it was the only measure of prior knowledge. Overall, the ability of our model to accurately classify group membership between good and excellent group students was lower than for weak and excellent group students.

The most effective model to predict group membership between weak and good group students is Model 3 including prior-GPA, beh-LS, and agen-Days (Nagelkerke $\mathrm{R}^{2}=.540$; see table 7). Model 3 was able to classify $85.1 \%$ of students accurately. This was higher than Model 2 with just the log data (Nagelkerke $\mathrm{R}^{2}=$ .468 ; model accuracy $=75.8 \%)$ or Model 4 (Nagelkerke $R^{2}=.488$; model accuracy $=80.5 \%)$. Individual significant variables across all models were beh-LS and prior-GPA.The prior-CP was not significant when it was used as the proxy for prior knowledge in model 4.

\section{DISCUSSION}

The purpose of this study was to use prior knowledge information and log data to better understand differences in student performance in our course, to inform our future teaching practices, and to guide other instructors who seek to use log data from their own blended courses with practical implications from this study. Findings suggest three ways this study helped us to understand our students and course. First, knowing students' prior knowledge can help us to judge if students are at risk to do poorly in the course, but GPA was more useful than our courselevel measure of prior knowledge. Second, there were different patterns of behavioral and agentic engagement across the three performance groups. Third, the most accurate models in predicting group membership included a combination of prior knowledge and engagement variables.

\section{Differences in Prior Knowledge across Performance Groups}

Generally, students entering a course with high prior knowledge of the content have an advantage because they are more likely to be able to learn the material (Greene et al., 2010). However, in this study the concept pre-assessment was only a significant predictor of group membership between excellent and weak group membership in the model that did not include GPA (see model 4 in table 5). Consistent with prior research about the importance of including measures of prior knowledge in student success research (e.g., Cogliano et al, 20 I8, Dunlosky et al., 20I3), findings indicated that GPA was a significant predictor of group membership for all three groups across all the models. The concept pre-assessment might not have been particularly useful in predicting group membership in this course because our learning-to-learn course is a process-oriented course rather than a content-orien-

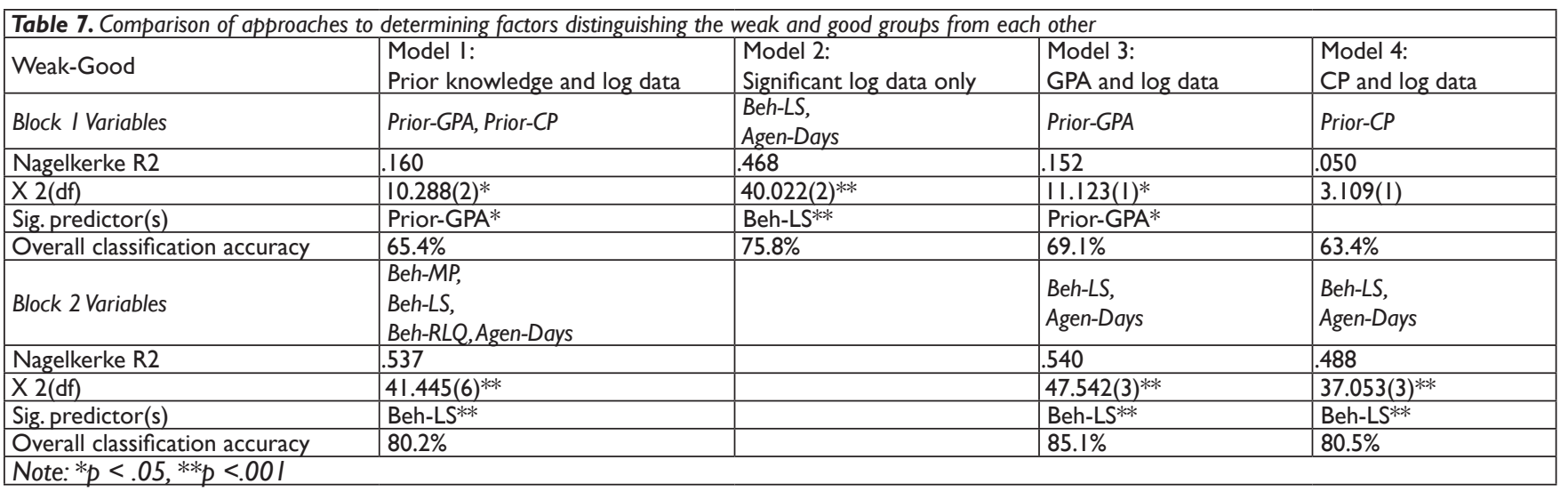


tated course. Student can know the content but fail to do well in the course because they did not demonstrate their processes in the various assignments. Going forward, if we want a measure of prior knowledge that is valuable in predicting student academic success across weak, good, and excellent performance we should revisit our concept pre-assessment measure and consider focusing the questions on procedural knowledge rather than declarative knowledge. It is also important to note the concept pre-assessment had some data missing and the analysis suggested that this data was most likely to be missing from the weak performance group. With a full set of data, the concept pre-assessment might be more useful in predicting group membership.

\section{Differences in Engagement across Performance Groups}

Categorizing the log data as either behavioral or agentic engagement revealed differences between the three performance groups. The measure of behavioral engagement was most useful to distinguish between weak and good performance, while the measure of agentic engagement was most useful to distinguish between good and excellent performance. In the first model comparing weak and excellent (see Table 4), agentic engagement did not distinguish between the weak and excellent groups. However, agentic engagement was significant across all other weak-excellent models. Further, across all analyses, the salient difference between the weak and good groups was that the good group completed more lecture synthesis activities than the weak group. This suggests good group students were either attending lectures more regularly or, if they did miss lecture, they more often logged on to complete the activity before the deadline.

Between the good and excellent groups, the salient difference was the excellent group students were logging on to the course more than the good group students. As we only counted the number of days the course was viewed, we do not know precisely the activities the excellent group students were doing. But rather their increased presence in the LMS was associated with higher overall performance. We would expect it was the range of activities those students engaged in while they were spending more time online, rather than simply online presence, which is associated with better performance. However, as our data did not capture the exact activities at this granularity, future research could investigate what high performing students are doing when they proactively access the course beyond instructor expectations.

These findings could imply that the types of engagement needed to prevent at-risk (weak) performance are different from the types of engagement needed for excellent performance. Therefore, in our course, each group may have to focus on different types of engagement to improve their performance. For the weak group, the focus of interventions could be on the behavioral engagement components of the course. These students should be encouraged to regularly attend lecture and labs. For good group students, the focus of intervention should be on maintenance of behavioral engagement and striving for agentic engagement. These students should take initiative when engaging with the course and not only complete the minimum course activity required by the syllabus. In the future, we should examine if these different intervention approaches work with our students.

Additionally, only one of the three behavioral engagement measures was useful in distinguishing between performance groups (beh-LS of beh-MP, beh-LS, and beh-RLQ), suggesting that some measures of engagement are more useful than others. We posit that beh-RLQ was not useful in distinguishing because of the low range $(0-2)$ and low variability $(S D=0.55)$. However, it is less clear why beh-LS was useful in distinguishing and beh-MP was not. These findings suggest that careful selection of engagement measures is critical as some of our behavioral engagement measures were not significant. However, this does indicate the benefit of having more than one indicator for engagement type, particularly for behavioral engagement. Thus, future research should incorporate multiple indicators of behavioral engagement unless the indicator has been found in previous studies to be significant and replication is the aim of the study.

\section{Predicting Student Performance by Comparing Models}

The focus of our second research question was to determine what logistic regression model was most accurate in predicting student performance in our course. All three of the most accurate models contained both prior knowledge and student engagement data. The most accurate model distinguishing between weak and excellent group students and between good and excellent group students contained the concept pre-assessment, GPA, and the engagement variables. The most accurate model distinguishing between weak and good group performance only contained GPA and the engagement variables. This indicates the concept pre-assessment was not as important in distinguishing between the weak and good groups. These findings reveal the importance of combining prior knowledge with contextualized student engagement data. Instructors who do not have access to students' previous GPAs could ask students to self-report prior GPA or to create a concept pre-assessment relevant to their own course content.

\section{PRACTICAL IMPLICATIONS}

This study informed our scholarship of teaching and learning for this course in both the course instruction and in how we intervene with students who wish to change their performance in the course.We also offer implications for other instructors who seek to support student academic success in their own courses.

\section{How Can We Support Student Academic Success in Our Course?}

We posit our data reveal at least two critical reasons why students do not engage fully with our course: Either (I) students do not recognize the importance of engaging in course activities or (2) students are not aware they are not engaging with course activities. We remedied this lack of task understanding through four interventions.

To address those students who do not recognize the importance of course engagement: First, we added an explicit description in the syllabus that explained the minimum number of times students should be accessing the course LMS is three times per week. Making this explicit helps inform students' procedural knowledge of the course and recognizes this course requires students to interact with the LMS in specific ways in order to be successful. Second, we provide recommendations to students who are concerned about their performance in the course based on the findings of this research. Specifically, students are advised of the importance of engaging in the course. For example, a weak performing student who is not engaging with the course material is advised to attend lecture and lab (i.e., behavioral engagement). 
Third, students are shown the findings from this study in the first lecture to help them direct their efforts throughout the course. Again, explaining these findings to students tries to make explicit the importance of engaging in course activities.

To address students who are not aware of their disengagement:We added a measure of academic engagement to the weekly online SRL diary tool (see Appendix I). We created the academic engagement measure to prompt students to think about these basic yet important steps to be successful. By adding this measure we supported students to increase their metacognitive knowledge of their engagement on a weekly basis. Rather than having students to rate their engagement using a Likert scale, we used a binary response scale (i.e., yes or no) to facilitate easier interpretation of items. For example, students either attended all their classes or they did not, students completed all their readings or they did not. Raising students' awareness gives them the opportunity to reflect on their patterns of engagement and make changes in those patterns over time. Students interpret this data during the course and reflect on how their engagement affects their use of SRL processes and strategies in the course. During an end of the semester paper, students reflect on their engagement and course progress and challenges.

\section{What Can All Instructors Do to Support Student academic success in Their Courses?}

Completing this study increased our understanding of the differences in student performance in our course. These findings may also encourage other instructors to use contextual knowledge of their own courses to explore the connections between behavioral and/or agentic engagement and performance, and then use their findings to support student academic success. We constructed a graphical representation of the constructs used in our study to be a practical resource for other instructors interested in the scholarship of teaching and learning (see Figure 3). This figure elaborates on Figure I and provides examples of indicators of prior knowledge, behavioral engagement, agentic engagement, and student performance. We included the specific data points we used in this study, as well as provided similar examples that may be present in other courses. Instructors can draw on these examples to identify prior knowledge, engagement, and performance variables to explore within their own courses. Researchers using log file data to improve student academic success may also benefit from drawing on these constructs and examples to consider the multiple factors affecting student learning.

Figure 3 defines each category and provides examples of indicators either that may already exist in courses or indicators instructors could add. When considering sources of students' prior knowledge, these could be knowledge about the domain, such as in our study, but can also include any knowledge held by an individual, e.g., declarative, procedural, self, contextual (Dochy, Segers, \& Buehl, 1999). Students' GPA may not be accessible to instructors, so instructors could ask students to self-report their overall GPA or final grade(s) in content-specific courses as one indicator of prior knowledge. However, the accuracy of these self-reported grades may need to be interpreted with caution (Kuncel et al., 2005), and might be more accurate for students with higher academic achievement (e.g., Caskie et al., 2017).

Therefore, depending on the course taught, instructors may give students a content-specific prior knowledge assessment to target aspects of prior knowledge most relevant to course material and learning. Behavioral and agentic engagement indicators can either be activities done in class or included in the LMS. Instructors could seek help from educational technologists at their universities to ensure they are making full use of the dynamic learning tools available in their LMS (Bates, 20I5). Specifically, for student performance, having a broader understanding of this cate-

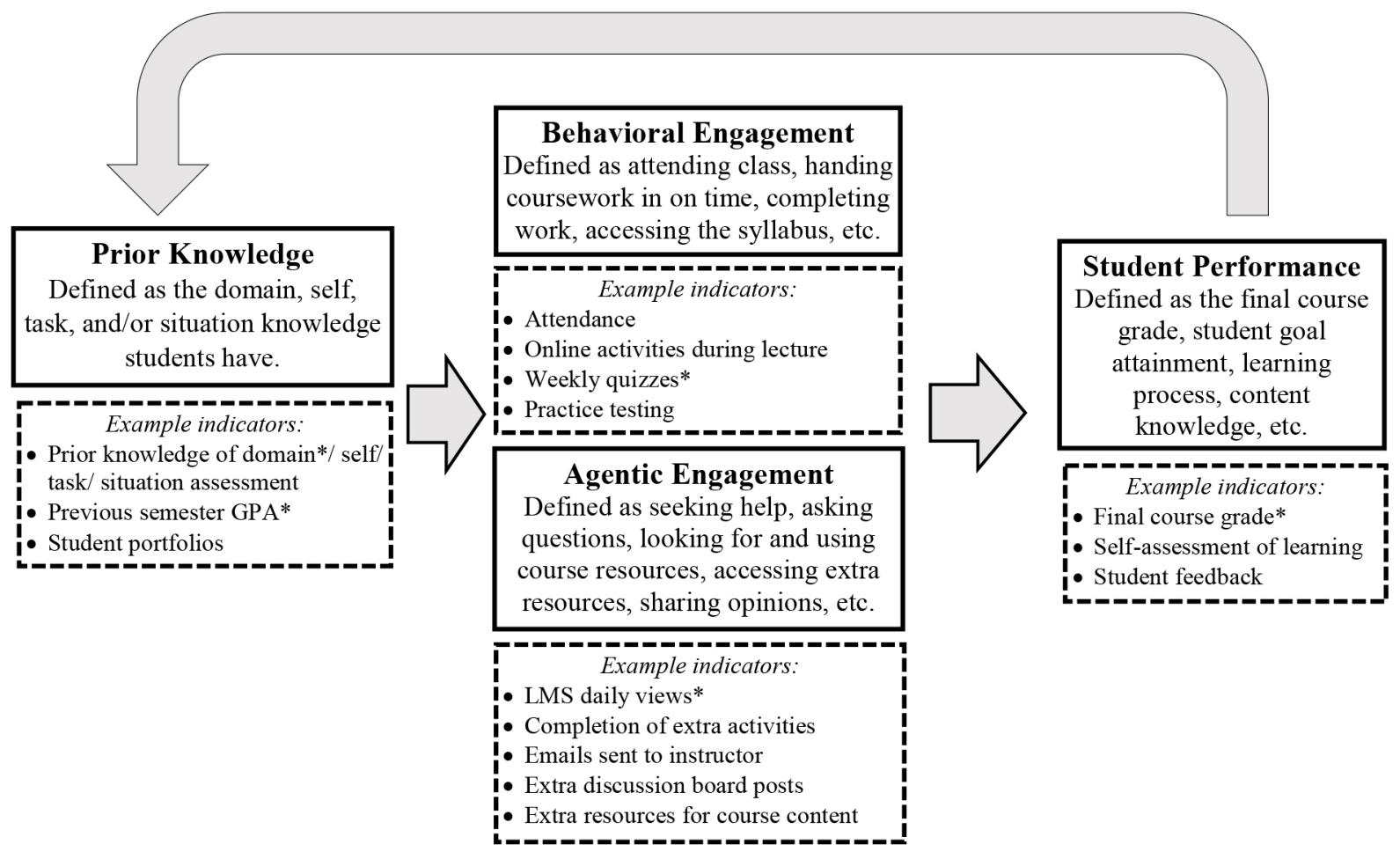

Figure 3. Graphic representation of how prior knowledge and engagement contribute to student performance in university courses. Example indicators marked with an asterisk were used in this study. 
gory may help instructors incorporate other ways of capturing students' progress in their courses. The final consideration in this figure is the addition of an arrow leading from student performance to prior knowledge. This arrow addresses the continuous nature of learning: what happens during one semester or learning event carries over into future semesters or learning events.

Identifying a few pivotal indicators of student academic success within a course based on the preceding parameters has the potential to help instructors implement interventions. For example, there may be a student who is doing well in the course and arranges a time to meet with the instructor to improve their understanding and extension of course materials. The instructor may notice the student had moderate prior knowledge and behavioral engagement, therefore focusing on indicators of the students' agentic engagement may provide options as to how the student can improve their performance in the course. This student may not be aware of other course material online and how this material could augment the students' knowledge and performance in the course. In particular, instructors can use the knowledge from these three areas when they notice students are at risk of failing the course. Students with lower prior knowledge who complete few practice testing opportunities and engage minimally with the LMS for the course are at risk of failing. These students may not be metacognitively monitoring their engagement, so it might be helpful for the instructor to prompt students to complete a weekly reflection, for example the academic engagement measure, to start to collect data on themselves so they can identify areas for improvement.

Finally, monitoring student engagement with course activities and resources on the LMS may provide students and instructors with valuable information. We recognize not all instructors are able to do this and/or not all courses use an LMS. However, leveraging the log file data available about the number of days students are accessing a course, for example, can provide valuable information for both students and instructors. In addition, putting this information explicitly in the syllabus would help students' awareness of what behaviours in the course are needed for success. For example, telling students how many days they should be engaging with the LMS and what students should be doing on the LMS are equally important. Basing recommendations to students on a combination of the factors in Figure 3 can provide individualized feedback and direction to foster student academic success.

\section{LIMITATIONS AND FUTURE DIRECTIONS}

Our research considers the factors associated with students' success, or performance, in a specific learning-to-learn course. This learning-to-learn course was a unique context to investigate the role of student engagement in student academic success because (a) the course revolved around the process of learning, and (b) success in the course relied on student's participating in self-regulated learning processes (e.g., goal setting, using strategies). Findings suggested both behavioral engagement and agentic engagement are critical to student academic success. This finding may not hold true in a course where success does not rely heavily on a student's process of adapting their learning approaches. Any use of log data and consideration of student engagement factors requires stakeholders to consider the course context carefully.

Using the theoretical framework of student engagement provides a promising direction for instructors hoping to better understand student academic success. Our findings suggest the actions students take within a course can be matched with some types of student engagement. Required activities in the syllabus can be used to represent behavioral engagement and actions going above-and-beyond syllabus requirements can be used to represent agentic engagement. However, it should be noted it is difficult to measure the types of student engagement in isolation. One student action may represent pieces of behavioral, cognitive, emotional, and agentic engagement.

Our analyses focused only on behavioral and agentic engagement because (a) these variables could be operationalized using course-based measures, and (b) Reeve (2013) found both self-reported behavioral and agentic engagement predicted academic achievement. The connections between student academic success and emotional and cognitive engagement warrant further investigation. For example, Sagayadevan \& Jeyaraj (2012) found emotional engagement partially mediated interactions between instructors and students and student learning. LMS and other educational technologies allow instructors, or researchers, to quickly pull out log data collected during the learning process and use this data to understand students and their learning. However, log data is purely a record of actions students have taken. Without more interpretation, log data cannot explain student emotions, thoughts, or intentions during actions. Future research on this learning-tolearn course will examine self-report measures to better understand the contribution of (a) emotional and cognitive engagement and (b) intent to student academic success.

We also highlighted the potential issues with one variable in our research, the concept pre-assessment, and how we dealt with missing data. If weak group students have more missing data than other groups, what implications does this hold for instructors aiming to better understand their students through data analysis? Future research should address how (a) analyzing patterns of missing data can be useful for instructor-researchers and (b) ways to remedy missing data in scholarship of teaching and learning research contexts.

\section{CONCLUSION}

Instructors who wish to use log data from their course may be overwhelmed at the amount of data they could potentially use. Examining the distribution of final grades from our undergraduate learning-to-learn course revealed different patterns of prior knowledge and engagement across the three performance groups. These patterns suggest students in the three groups may require different types of intervention or encouragement from instructors. Conducting this research helped us to identify factors within our course contributing to differences in student performance and the information will assist both us as the instructors and future students in the course. While other contexts may not have the same findings, organizing data according to student engagement factors and prior knowledge may have potential for instructors using log data to examine differences in student academic success. Our graphical representation (i.e., figure 3 ) offers instructors a guide to identify potential data sources in their own courses and take steps toward understanding how students are engaging with their course material. 


\section{ACKNOWLEDGEMENTS}

Support for this research was provided by an Insight Grant for research to Hadwin, A.F., \& Winne P.H. from the Social Sciences and Humanities Research Council of Canada (435-20I2-0529) and a SSHRC Joseph-Armand Bombardier Master's Scholarship awarded to R. L. Edwards.

\section{REFERENCES}

Appleton, J. J., Christenson, S. L., \& Furlong, M. J. (2008). Student engagement with school: Critical conceptual and methodological issues of the construct. Psychology in the Schools, 45, 369-386. https://doi.org/10.1002/pits.20303

Bandura, A. (2008b). An agentic perspective on positive psychology. In S. J. Lopez (Ed.), Positive psychology: Exploring the best in people, I, I67-196. Westport, CT: Greenwood Publishing Company.

Bates,A.W. (20I5). Teaching in a digital age: Guidelines for designing teaching and learning. Retrieved from https://opentextbc.ca/ teachinginadigitalage/

Caskie, G.I.L., Sutton, M.C., \& Eckhardt, A.G. (20I4). Accuracy of self-reported college GPA: Gender-moderated differences by achievement level and academic self-efficacy. Journal of College Student Development 55, 385-390. https://doi. org/ $10.1353 /$ csd.20I4.0038

Choi, J. N., \& Moran, S. V. (2009). Why not procrastinate? Development and validation of a new active procrastination scale. The Journal of Social Psychology, 149, 195-212. https:// doi.org/I0.3200/SOCP.I49.2.195-2I 2

Cogliano, M., Kardash, C. M., \& Bernacki, M. L. (2019). The effects of retrieval practice and prior topic knowledge on test performance and confidence judgments. Contemporary Educational Psychology, 56, I I7-129. https://doi.org/10.1016/j. cedpsych.2018.12.00।

Dochy, F., Segers, M., \& Buehl, M. M. (1999). The relation between assessment practices and outcomes of studies: The case of research on prior knowledge. Review of Educational Research, 69(2), | 45- | 86.https://doi.org/ | 0.3 | 02/00346543069002 | 45

Dunlosky, J., Rawson, K. A., Marsh, E. J., Nathan, M. J., \& Willingham, D.T.(20I3). Improving students' learning with effective learning techniques: Promising directions from cognitive and educational psychology. Psychological Science in the Public Interest, /4, 4-58. https://doi.org/I0.I I 77//1529I006I245

Eccles, J. S., Adler, T. F., Futterman, R., Goff, S. B., Kaczala, C. M., Meece, J. L., et al. (1983). Expectancies, values, and academic behaviors. In J. T. Spence (Ed.), Achievement and achievement motivation (pp. 75-146). San Francisco, CA: Freeman.

Finn, J. (1993). School engagement and students at risk. National Center for Education Statistics Research and Development Reports. Retrieved from: https://nces.ed.gov/pubs93/93470a. pdf

Fredricks, J. A., Blumenfeld, P. C., \& Paris, A. H. (2004). School engagement: Potential of the concept, state of the evidence. Review of Educational Research, 74, 59-109. https://doi. org/ I0.3102/00346543074001059

Fritz, J. (20II). Classroom walls that talk: Using online course activity data of successful students to raise self-awareness of underperforming peers. The Internet and Higher Education, 14, 89-97. https://doi.org/10.1016/j.iheduc.2010.07.007

Fyfe, E. R., \& Rittle-Johnson, B. (2016). Feedback both helps and hinders learning:The causal role of prior knowledge. Journal of Educational Psychology, 108, 82-97.https://doi.org/1 0.1037/ edu0000053

Greene, J. A., Costa, L. J., Robertson, J., Pan, Y., \& Deekens, V. M. (2010). Exploring relations among college students' prior knowledge, implicit theories of intelligence, and self-regulated learning in a hypermedia environment. Computers \& Education, 55, 1027-1043. https://doi.org/10.1016/j.compedu.2010.04.013

Kahu, E. R. (2013) Framing student engagement in higher education. Studies in Higher Education, 38, 758-773, https://doi.org/ I0.1080/03075079.2011.598505

Kalyuga, S., Chandler, P., \& Sweller, J. (1998). Levels of Expertise and Instructional Design. Human Factors, 40, I-17. https:// doi.org/I0.15 I8/001872098779480587

Kim, D., Park,Y.,Yoon, M., \& Jo, I. H. (20I6). Toward evidence-based learning analytics: Using proxy variables to improve asynchronous online discussion environments. The Internet and Higher Education, 30, 30-43. https://doi.org/10.1016/j.iheduc.2016.03.002

Kuncel, N. R., Credé, M., \& Thomas, L. L. (2005). The validity of self-reported grade point averages, class rank, and test scores: A meta-analysis and review of the literature. Review of Educational Research, 75, 63-82. https://doi. org/10.3102/00346543075001063

Macfadyen, L. P., \& Dawson, S. (2010). Mining LMS data to develop an "early warning system" for educators: A proof of concept. Computers \& Education, 54, 588-599. https://doi. org/10.1016/j.compedu.2009.09.008

National Survey of Student Engagement (NSSE). 2005. Exploring different dimensions of student engagement. Bloomington: Indiana University Center for Postsecondary Research. http:// nsse.iub.edu/NSSE_2005_Annual_Report/index.cfm

Pardo, A. (20|4). Designing learning analytics experiences. In J.A. Larusson \& B.White (Eds.), Learning Analytics: From Research to Practice (pp. 15-38). New York, NY: Springer. https://doi. org/| 0.1007/978-I-46|4-3305-7_2

Reeve, J. (20I3). How students create motivationally supportive learning environments for themselves: The concept of agentic engagement. Journal of Educational Psychology, 105, 579595. https://doi.org/10.1037/a0032690

Reeve, J., \& Tseng, C. M. (20I I). Agency as a fourth aspect of students' engagement during learning activities. Contemporary Educational Psychology, 36, 257-267. https://doi.org/10.1016/j. cedpsych.201 I.05.002

Richter, J., Scheiter, K., \& Eitel,A. (2016). Signaling text-picture relations in multimedia learning: A comprehensive meta-analysis. Educational Research Review, 17, 19-36. http://dx.doi. org/10.1016/j.edurev.2015.12.003

Roll, I., \& Winne, P. H. (20I5). Understanding, evaluating, and supporting self-regulated learning using learning analytics. Journal of Learning Analytics, 2, 7-12. https://doi.org/10.18608/ jla.20I5.21.2

Sagayadevan, V., \& Jeyaraj, S. (20I2). The role of emotional engagement in lecturer-student interaction and the impact on academic outcomes of student achievement and learning. Journal of the Scholarship of Teaching and Learning, 12, I-30. Retrieved from https://scholarworks.iu.edu/journals/index. $\mathrm{php/josotl/article/view/2I52}$

Schmidt, J. A., Rosenberg, J. M., \& Beymer, P. N. (2018). A personn-in-context approach to student engagement in science: 
Examining learning activities and choice. Journal of Research in Science Teaching, 55, 19-43. https://doi.org//0.1002/tea.21409

Shapiro,A. M. (2004). How including prior knowledge as a subject variable may change outcomes of learning research. American Educational Research Journal, 4I, 159-189. https://doi. org/I0.3102/000283 I204I00II59

Sharkey, J. D., Quirk, M., \& Mayworm, A. M. (20I4). Student engagement. In T. R. Gilman, E. S. Huebner \& M. J. Furlong (Eds.) In Handbook of positive psychology in schools, 176-191. https:// doi.org// 0.4324/9780203 106525.ch 12

Siemens, G. (2013). Learning analytics: The emergence of a discipline. American Behavioral Scientist, 57, I380-|400. https://doi. org/ I 0. I I 77/00027642 I349885 I

Siemens, G., \& Baker, R. S. (20I2). Learning analytics and educational data mining. Proceedings of the 2nd International Conference on Learning Analytics and Knowledge - LAK' 12 https:// doi.org/ I0.1 I45/233060I.233066I

Siemens, G., \& Gašević, D. (20I2). Guest editorial - Learning and knowledge analytics. Educational Technology \& Society, I5, I-2. Retrieved from: https://www.j-ets.net/ETS/journals/I5_3/I. pdf

Siemens, G., \& Long, P. (20I I). Penetrating the fog: Analytics in learning and education. EDUCAUSE review, 46(5), 30. Retrieved from http://er.educause.edu/articles/201 l/9/penetrating-the-fog-analytics-in-learning-and-education

Simonsmeier, B. A., Flaig, M., Deiglmayr, A., Schalk, L., \& Schneider, M. (20 18, June). Domain-specific prior knowledge and learning:A meta-analysis. Paper session presented at Research Synthe- sis 2018, Trier, Germany. http://doi.org//0.23668/psycharchives.844

Soffer, T. \& Cohen, A. (2019). Students' engagement characteristics predict success and completion of online courses. Journal of Computer Assisted Learning, 35, 378-389. https://doi. org/ I0. I I I I/jcal. I 2340

Tempelaar, D. T., Rienties, B., \& Giesbers, B. (20I5). In search for the most informative data for feedback generation: Learning Analytics in a data-rich context. Computers in Human Behavior, 47, 157-167. https://doi.org/10.1016/j.chb.2014.05.038

Trowler, V. (2010). Student engagement literature review. The Higher Education Academy, I I, I- I5. Retrieved from: https:// www.heacademy.ac.uk/system/files/studentengagementliteraturereview_l.pdf

Turner, J. C., Gray, D. L., Anderman, L. H., Dawson, H. S., \& Anderman, E. M. (20/3). Getting to know my teacher: Does the relation between perceived mastery goal structures and perceived teacher support change across the school year?. Contemporary Educational Psychology, 38, 316-327 https://doi. org/I0.1016/j.cedpsych.2013.06.003

Winne, P. H., \& Baker, R. S. (20I3). The potentials of educational data mining for researching metacognition, motivation and self-regulated learning. Journal of Educational Data Mining, 5(I), I-8. Retrieved from: https://jedm.educationaldatamining.org/index.php/JEDM/article/view/28

Winne, P. H., \& Hadwin, A. F. (1998). Studying as self-regulated learning. In D. J. Hacker, J. Dunlosky, \& A. C. Graesser (Eds.), Metacognition in EducationalTheory and Practice. (pp. 277-304). Mahwah, NJ: Lawrence Erlbaum. 


\section{APPENDIX 1. ACADEMIC ENGAGEMENT MEASURE}

\begin{tabular}{ll}
\hline Item & Reponse \\
\hline I attended all classes in my courses & Yes / No \\
I met all my deadlines in all my courses & Yes / No \\
I did all my assignments in my courses & Yes / No \\
I completed all the assigned readings in my courses & Yes / No \\
I asked for help when I didn't understand something in my courses & Yes / No \\
I tried to summarize what I learned in my courses & Yes / No
\end{tabular}

